\title{
A Note on the Formation of the Egg Case of the Skate.
}

\author{
By \\ A. D. Hobson, M.A., \\ Lecturer in Experimental Zoology, University_of Edinburgh.
}

With 2 Figures in the Text.

THERE seems to be some uncertainty about the exact stage at which the horny case is secreted around the fertilised Elasmobranch egg. Those textbooks which have been consulted either pass over the matter in silence or give the impression that the shell is secreted while the egg is passing through the nidamental organ. Sedgwick (1905), for example, says (p. 143) : "The shell is formed round the ovum and its albumen in the lower dilated part of the oviduct, but the material of which it is composed is secreted by the oviducal gland." Of late years the question seems to have received little attention, but there are several papers on the subject published twenty or more years ago.

Gerbe (1872) considered that in rays the albumen and shell are secreted simultaneously round the egg. He observed: "Un œuf à moitié engagé dans la glande, et qui possède une partie de son albumen, possède en meme temps une partie de sa coque."

Perravex (1884) investigated the structure of the nidamental organ of Scyllium canicula and discovered "dans une glande nidamenteuse de Scyllium canicula un œuf à demi engagé; les cornes antérieures et la partie inférieure seules étaient formées. . . ." His conclusion was that, although secretion of the matter of which the shell is composed begins before the egg reaches the gland, yet the shell is actually formed around the egg.

Borcea (1904) concluded that formation of the shell begins before the egg reaches the nidamental organ on the ground that the pressure of the egg within the gland would prevent the secretion from passing between the lamellæ at the base of which the individual tubular glands open. He considered that "Le phenomène se passe d'une manière reflexe : l'œuf n'est qu'un stimulus qui le détermine." He did not, apparently, come across any specimens directly confirming his view, although he cited the occurrence of fully-formed egg cases containing only albumen as showing that the egg is not the only stimulus which can cause the secretion of a shell. 
The most extensive paper on this subject is that of Widakowich (1906), who described the structure of the nidamental organ of Scyllium canicula in great detail and endeavoured to deduce the process of shell formation from his observations. He recognised that the caudal processes of the egg case are laid down during the passage of the egg down the part of the oviduct cranial to the nidamental organ. He thought, however, that the body of the case is formed during the subsequent movement of the egg through the gland. He found one specimen in which the anterior part of the egg case had not been completely formed, but here, apparently, the egg had already passed through the nidamental organ and was lying in the already fully-formed part of the case in the caudal region of the oviduct.

Beard (1890) stated that in skates, "It appears very likely, nay, almost certain, that the lower half of the purse is formed before the egg arrives at the oviducal gland, and that after the arrival of the egg the closure of the purse is at once effected." This conclusion, which is in complete agreement with the observations to be described in the present note, was based on the following circumstances. Firstly, "One often finds part of a purse in the oviduct and no yolk or egg within it." Secondly, about 10 per cent of some shark egg cases laid in captivity were found to contain no egg. It is unfortunate, with regard to the first observation, that it is not stated whether an egg was present in the oviduct.

It may be seen from the above references that, although intermediate stages in shell formation in Elasmobranchs have on several occasions been observed, there is a lack of precision in the descriptions which renders it difficult to draw definite conclusions as to the sequence of events in this process, Consequently, it is thought that the following observations may be of interest although they are based only on a single specimen of Raia radiata Donovan. Beard (1890) states that breeding specimens of this species are rare in the Firth of Forth. Raia radiata is now, however, the commonest species among those dissected in the Department of Zoology in the University of Edinburgh ( $c f$. Lamont, 1926), and individuals containing egg cases are fairly plentiful.

Pregnant individuals almost invariably are found with one or two fullyformed and closed egg cases in the part of the oviducts posterior to the nidamental organ or in the vagina. Occasionally a specimen may be noticed in which the anterior horns of the cases are still within the nidamental organ. The exception to be described in which the egg cases are only half formed is the only one which has been noticed in such a condition among, at a rough estimate, 150 pregnant female skate of several species. This indicates that, once ovulation has taken place, the passage of the egg down the cranial part of the oviduct and the formation of the shell is accomplished quickly.

A general view of the specimen of Raia radiata, on which the following 
observations are based, is seen in Fig. 1. The liver and alimentary canal have been removed in order to display the reproductive organs. The left ovary has been turned over towards the middle. Anterior to the nidamental organ (N.O.) each oviduct is swollen by a mature ovum (Od.) which is yet devoid of either white or shell. Behind the nidamental organ on either side the oviduct is greatly distended by the posterior half of the egg case (E.C.), whose vague outlines can be distinguished through the

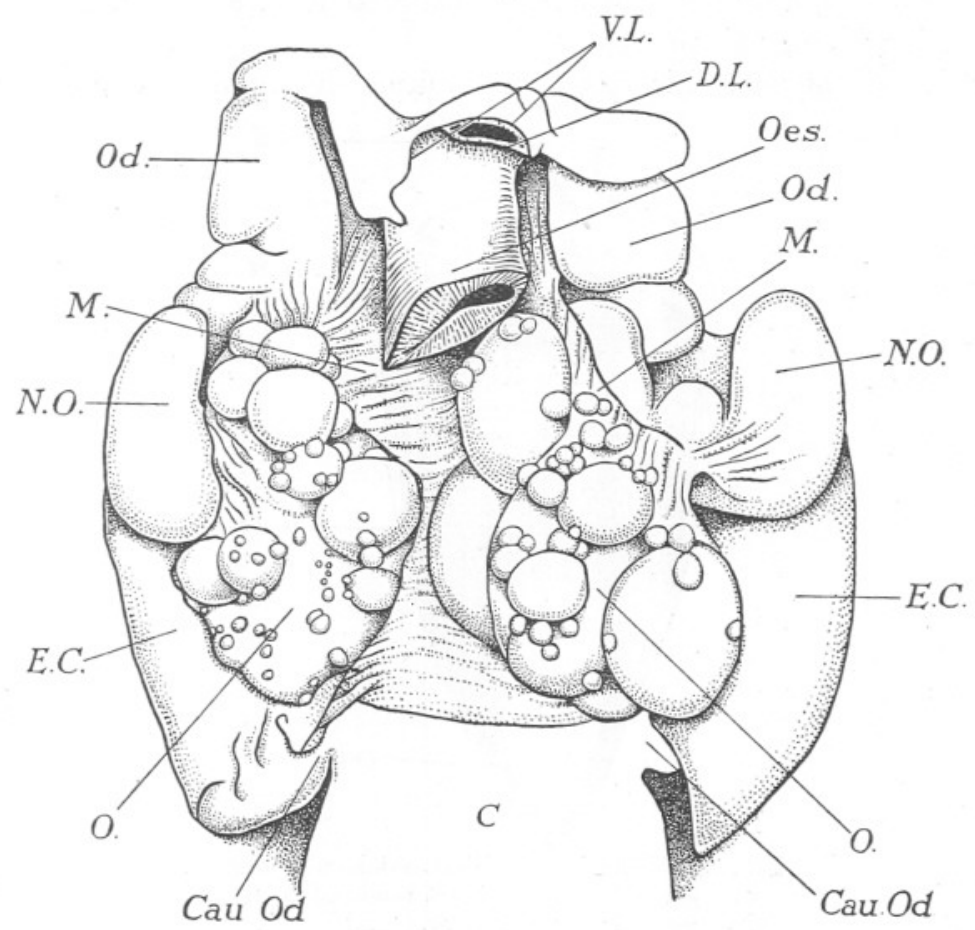

FIG. 1.-O., ovary; M., mesovarium; D.L., V.L., dorsal and ventral lips of oviducal funnels; Od., ovum in cranial part of oviduct; N.O., nidamental organ ; E.C., egg case in caudal part of oviduct; Cau. Od., undistended part of caudal oviduct; C., cloaca; Oes., oesophagus. (Nat. size.)

oviducal wall. Behind the egg case each oviduct is at liberty to retain its normal diameter and turns sharply towards the middle line to join that of the other side to form the cloaca (C.). Fig. 2 shows the condition of the egg case. The ventral half of the left nidamental organ and of the oviduct immediately posterior to it has been removed. The egg case (E.C.) can be seen lying in the distended part of the caudal oviduct. At O.U. is the opening into the yet undistended part of the oviduct. About half of the egg case has already been formed. Its only difference from the final product is that it is lighter in colour and somewhat softer. Widakowich 
(1906) has pointed out that the case of Scyllium canicula is formed by a large number of separate elements ("Platten ") which adhere to each other comparatively loosely at first but later, and especially after contact with sea-water, much more closely so that the whole shell hardens.

The half-formed egg case is quite empty. Its dorsal and ventral walls are well separated from one another so that at the anterior end there is an opening which will admit the egg when it is ready to pass into the case. It is probable, however, that the egg has to undergo a certain amount of distortion during this process.

It is evident that this specimen confirms the opinions expressed by

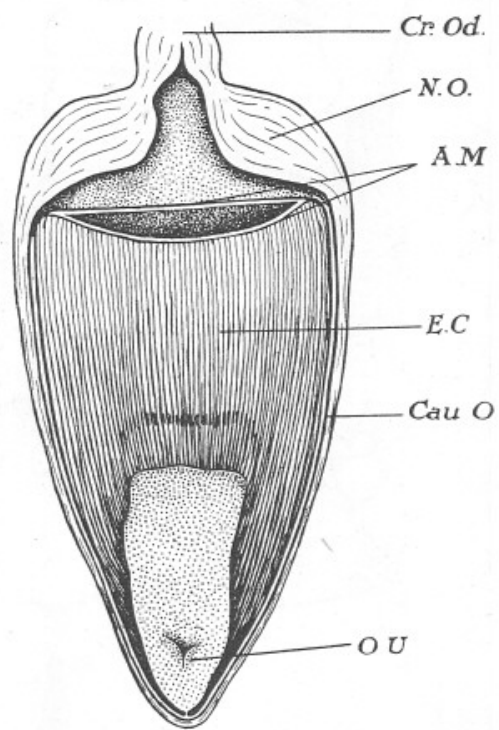

FIG. 2.-Ventral half of left nidamental organ and part of caudal oviduet removed to show half-formed egg case in situ. $(\times 2$.

Cr. Od., cranial part of oviduet; N.O., nidamental organ; Cau. O., caudal part of oviduct; o.U. opening into undistended part of caudal oviduct; E.C., egg case ; A.M., anterior margin of egg case.

Beard (1890) and by Borcea (1904), although neither of these workers presented critical evidence in favour of their views. At least half, and possibly considerably more, of the egg case is already formed before the egg comes into contact with the nidamental organ at all. Various authors (e.g. Perravex, Widakowich) have described the presence of shell material already secreted in the tubules of the shell gland before the egg has even been shed from the ovary. It is probable, therefore, that the shell gland commences activity some time before ovulation occurs. The scarcity of observations between this period of preparation and the fully-formed 
egg case with the egg enclosed, suggest that once the egg has reached the oviduct, events move rapidly.

It is a familiar fact that two ova are shed from the ovaries simultaneously, so that in each oviduct there is an egg in the same stage of development. In the specimen here described it may be noted that both eggs appear to have been shed from the right ovary. In Fig. 1 it can be seen that in the left ovary are several eggs in an advanced stage of development, whereas in the right ovary the largest eggs present are only about halfgrown. This may indicate an alternation in the activity of the ovaries. Many further observations would be needed to establish this, but if it should prove to be generally true, it may readily be seen how, from such a condition, that found in Scyllium canicula, for example, could be derived, in which only one ovary develops and becomes functional.

One further point is illustrated in Fig. 1. In textbooks the oviducal funnels of both the skate and the dogfish are described and figured as being united to form a single median ostium. In Raia radiata, at any rate, this seems not to be the case. The upper and lower lips of the funnels are, indeed, united, but the openings remain so widely separated as to be, probably, functionally distinct. Redeke (1898) stated that in Trygon pastinaca there are two separate ostia (quoted by Ihle, 1927, p. 745). Raia radiata, therefore, seems to exhibit a condition intermediate between this and the completely fused ostia of Raia batis.

\section{REFERENCES.}

Beard, J. On the development of the common skate. Fisheries, Scotland, 8th Annual Report, Pt. III, 1890.

Borcea, I. Sur la glande nidamentaire de l'oviducte des Élasmobranches. C. R. Acad. Sci., Paris, Vol. 138, p. 99, 1904.

Gerbe, Z. Recherches sur la segmentation de la cicatricule et la formation des produits adventifs de l'oeuf des Plagiostomes et particulièrement des Raies. Journ. de l'Anat. et de la Physiol., Vol. 8, p. 609, 1872.

Ihle, J. W. E. Vergleichende Anatomie der Wirbeltiere. Berlin, 1927.

Lamont, A. Relative frequency of species and sex-ratios in the skates and rays (genus Raia). Proc. Roy. Physical Soc., Edinburgh, Vol. 21, 1926.

Perravex, E. Sur la formation de la coque des œufs du Scyllium canicula et du Scyllium catulus. C. R. Acad. Sci., Paris, Vol. 99, p. $1080,1884$.

Sedawick, A. A student's textbook of zoology. Vol. II, London, 1905.

Widakowich, V. Ueber Bau und Funktion des Nidamentalorgans von Scyllium canicula. Zejtschr. wiss. Zool., Vol. 80, p. 1, 1906. 
